we come to our senses and see this for the lie that it is?

Let me take this opportunity to encourage you not to be afraid to inform a patient when appropriate, that you can acknowledge that they have difficulties in life but that it is not a mental illness.

Frederick II, King of Prussia is supposed to have shouted to his men as he led them into battle:

'What's wrong, you dogs! Do you want to live forever?'

I have little doubt that had he been a doctor he would not have over diagnosed mental illness.

Anthony J McElveen,

MRCGP, MRCPsych, Department of Psychiatry, Stobhill Hospital, Glasgow. E-mail: dr.mcelveenadoctors.org.uk

DOI: 10.3399/bjgp13X660670

\section{Depersonalisation in GPs}

We thank the Editor and Dale and Old ${ }^{1}$ for commissioning and writing an interesting commentary on our research on depersonalistion as a form of burnout in GPs.

Given that we received the biggest number of completed Maslach Inventories so far reported (564 GPs, with 42\% depersonalised), we agree the findings merit serious attention. Their practical suggestions, such as making time for a weekly lunch between colleagues, in our experience, work well.

We, too, are interested in the finding that females suffered less depersonalisation and agree females may have much to contribute to considering responses. However, we are cautious about this finding since, as we stated, we did not have data on part-time working. We suspect that part-time working (much more common in females) may be protective against burnout.

We think it is very helpful that Dale and Old distinguish between depersonalisation as we used it las defined by the Maslach Inventoryl and the psychiatric state they describe. Although doctors may lose insight when depersonalised, our new finding was that they still maintain a professional face, so that patients answering questionnaires, did not perceive the depersonalised doctors as being different from other doctors.

We do not agree that a degree of depersonalisation (cynical feelings towards patients) is necessary. Maintaining a safe emotional distance is a skill GPs need to learn, but not at the cost of cynicism. As they write, our results show that most GPs achieve it.

Dale and Old undervalue doctors consulting GPs for stress. The two of us who are experienced GPs (PO and $D P G$ ) have both had the privilege of being consulted by several fellow doctors over many years. Doctors as patients do indeed have special difficulties, but with clear agreements, ground rules on privacy, adequate time, and personal care with continuity. We believe valuable support and treatment can be and often is provided for consultants and GPs within general practice. Indeed, this may be the optimal setting for care.

Peter Orton,

Aviation Medica, London Stansted Airport, CM24 1RY. E-mail: peter-ortonamsn.com

Christopher Orton,

Aviation Medica, London Stansted Airport.

Denis Pereira Gray,

Aviation Medica, London Stansted Airport.

\section{REFERENCES}

1. Dale S, Old J. Maintaining professionalism in the face of burnout. Br J Gen Pract 2012; 62(604): 605-607.

2. Orton P, Orton C, Pereira Gray D. Depersonalised doctors: a cross-sectional study of 564 doctors, 760 consultations and 1876 patient reports in UK general practice. BMJ Open 2012; 2(1): e000274.

DOI: 10.3399/bjgp13X660689

\section{Corrections}

Table 1 headings were incorrectly published in an article from the June issue of the journal: Francis, et al. Antibiotics for acute cough: an international observational study of patient adherence in primary care. Br J Gen Pract 2012; DOI: 10.3399/ bjgp12X649124. The column headings from left to right should read: 'Network', 'Number of participants', 'Number prescribed antibiotics (for immediate use)',
'Initiated antibiotics (consumed at least 1 day)', 'Adhered to at least a 3-day course of antibiotics'. 'Adhered to full prescribed antibiotic course', 'Consumed an antibiotic at any point during study follow period'. Data below these headings are in the correct order but do not match with the incorrect column headings. We apologise for these errors.

\section{DOI: 10.3399/bjgp13X659609}

An error was made in the Figure 2 legend of an article published in the September 2012 issue: Francis et al. Delayed antibiotic prescribing and associated antibiotic consumption in adults with acute cough. Br J Gen Pract 2012; DOI: 10.3399/ bjgp12X654614. The green section of the legend should have stated: 'Prescribed antibiotics for delayed use and no antibiotics consumed during the study period', and blue should be, 'Prescribed antibiotics for delayed use and consumed prescribed antibiotics during the study period'. We apologise for this error.

DOI: 10.3399/bjgp13X659618

Results were shown incorrectly in the abstract and Results section of the article by Mugunthan et al. Minimal interventions to decrease long-term use of benzodiazepines in primary care: a systematic review and meta-analysis. Br J Gen Pract 2011; $10.3399 /$ bjgp 11X593857. Findings in the abstract were $(2.1,95 \%$ confidence interval $[\mathrm{Cl}]=1.5$ to 2.9 , whereas these should have been: $2.04,95 \%$ confidence interval $[\mathrm{Cl}]=1.5$ to 2.8 . And in the Results section it stated: $2.3(95 \% \mathrm{Cl}=1.3$ to $4.2, P=$ $0.003)$, but should have read: $2.3(95 \% \mathrm{Cl}=1.3$ to 4.2 , $P=0.008)$. We apologise for these errors.

\section{DOI: 10.3399/bjgp13X660706}

Author affiliations were incorrectly shown in the December 2012 article: Middlemass et al. Integrating online communities and social networks with computerised treatment for insomnia: a qualitative study. Br J Gen Pract 2012: DOI: 10.3399/ bjgp12X659321. The affiliation for Jo Middlemass was listed as School of Sport, Exercise \& PreHospital Health Care, University of Lincoln, Lincoln, whereas it should have been Lincoln School of Health and Social Care, University of Lincoln, Lincoln; Kevin Morgan was listed at School of Sport, Exercise \& Pre-Hospital Health Care, University of Lincoln, Lincoln but should have been School of Sport, Exercise and Health Sciences, Loughborough University, Loughborough; and A Niroshan Siriwardena was listed at School of Sport, Exercise \& Pre-Hospital Health Care, University of Lincoln, Lincoln, but this should have been Lincoln School of Health and Social Care, University of Lincoln, Lincoln. We apologise for these errors.

DOI: 10.3399/bjgp13X660715 